TAO, Vol. 14, No. 1, 27-40, March 2003

\title{
Tectonic Implications of 1998, Ruey-Li, Taiwan, Earthquake Sequence
}

\author{
Chau-Huei Chen ${ }^{1, *}$, Wei-Hau Wang ${ }^{2}$, and Ta-Liang Teng ${ }^{3}$ \\ (Manuscript received 15 May 2002, in final form 2 December 2002)
}

\begin{abstract}
We carried out a seismotectonic study on the 1998 Ruey-Li, Taiwan earthquake. This $M_{L}=6.2$ event occurred in a close neighborhood to and about one year before the $M_{w}=7.6$ disastrous Chi-Chi, Taiwan earthquake of 1999. Both the Ruey-Li and the Chi-Chi events share a common regional stress system. From the relocated hypocenters, focal mechanisms and stress inversion of the Ruey-Li sequence, we find that the spatial distribution of aftershocks forms two distinct groups, one is consistent with a planar thrust, the other gives a peculiar $3 \mathrm{~km} \times 5 \mathrm{~km} \times 15 \mathrm{~km}$ of nearly vertical columnar distribution made principally of left-lateral strike-slip faulting. A regional block rotation model is proposed to explain the rup. ture process; this model is supported by the well-documented GPS data.
\end{abstract}

(Key words:Tectonic stress, Double differential travel time)

\section{INTRODUCTION}

The damaging Ruey-Li, Taiwan earthquake, magnitude $\mathrm{M}_{\mathrm{L}}^{\prime}=6.2$, occurred on July 17, 1998 in southwestern Taiwan, roughly $25 \mathrm{~km}$ to the northeast of the large city of Chia-Yi. This event was followed by an energetic but unusually short (about one week) aftershock sequence with a peculiar spatial distribution. About one year later, the disastrous $\mathrm{M}_{\mathrm{w}}=7.6$ Chi-Chi, Taiwan earthquake initiated a short distance north of the Ruey-Li epicenter with a similar but thrust mechanism with a 80-km long surface break coming close to the Ruey-Li epicenter. According to the Central Weather Bureau Seismic Network (CWBSN) report, the number of aftershocks was hundreds per day for the first 3 days, but decreased rapidly to several per day and ended abruptly in about a week. The epicenter of the main-shock was located in the CWBSN report at $23^{\circ} 30.16^{\prime} \mathrm{N}$ and $120^{\circ} 39.75^{\prime} \mathrm{E}$, with a focal depth of $2.8 \mathrm{~km}$.

\footnotetext{
${ }^{1}$ Institute of Seismology, National Chung Cheng University, Chia-Yi, Taiwan, ROC

${ }^{2}$ Institute of Applied Geophysics, National Chung Cheng University, Chia-Yi, Taiwan, ROC

${ }^{3}$ Department of Earth Sciences, University of Southern California, Los Angeles, CA, USA.

* Corresponding author address. Prof. Chau-Huei Chen, Institute of Seismology, National Chung Cheng University,Chia-Yi, Taiwan, ROC; E-mail: seichen @eq.ccu.edu.tw
} 
The fault plane solution for the mainshock is an oblique thrust; for the larger aftershocks (Chen et al. 1999), two types of focal mechanism are shown: strike-slip in one larger cluster and thrust in the smaller cluster. A shallow event, the Ruey-Li earthquake caused landslides, rock falls and damage to buildings, and injured more than 25 people.

The source area of the 1998 Ruey-Li earthquake is located on the western margin of the Westem Foothills province. The geological survey shows a thick sequence of shallow marine to shelf clastic sediments ranging in time from late Oligocene and Miocene to early Pleistocene in this area (Huang 1980). Figure 1 shows the major fault system of the study area as mapped by surface geology. The dominant structure is a combination of asymmetric folds and low-angle thrust faults striking northeast and dipping southeast, a result of deformed rocks in the Western Foothills (Ho 1976; Suppe 1980). The roughly parallel thrust faults from west to east are the Tachienshan fault, the Chukou fault, the Shihkuping fault, the Luku fault and the Shechiunhu fault. There are two northwest-trending left-lateral strike-slip faults: the Shuisheliao and Neipang. The southern part of the Tachienshan fault and the northern part of the Neipang fault show significant variation in strike and slip direction. The Tachienshan fault, northern segment of the Chukou fault, separates the area into two distinct geological structures (Liu and Lee 1998). The structural manifestation to the west of the Tachienshan fault is simple with gentle folds and fewer faults, while those to the east are complex with tighter folds and many faults (Keng 1986). The faults trending northeast were probably formed later in the event and were followed by northwest-southeast striking and left-lateral strike-slip faults (Tsan and Keng 1962; Liu and Lee 1998). The folds striking in the northeast may have been formed during the earlier Penglai Orogeny of Plio-Pleistoce time (Liu and Lee 1998).

However, no surface break was observed. We have relocated 98 events (Table 1) that occurred within the period of 24 hours after the mainshock. Improved locations give two tighter clusters than those given by the CWBSN. This paper focuses on the analysis of focal mechanisms and stress inversion for a discussion on the seismotectonic significance of the Ruey-Li earthquake vis-a-vis the regional structural and deformation background. We have also calculated the stress induced by the mainshock of the earthquake sequence to discuss whether the slip of the mainshock affected the distribution of aftershocks, and whether it triggered some nearby faults, as indicated by aftershocks with different focal mechanisms and locations.

\section{DATA AND ANALYSIS}

\subsection{Earthquakes Relocation}

The Ruey-Li earthquake sequence was well recorded by the CWBSN short-period network and strong-motion telemetered stations. The dense nearby free-field stations of the Taiwan Strong-Motion Instrumentation Program (TSMIP) also contributed data of both the relative arrival times and P-polarities. The hypocenters of the Ruey-Li earthquake sequence had been routinely obtained by 1-D crustal model by CWBSN (e.g., CWB report 1999); improvements can be made by using an appropriate 3-D crustal model to account for lateral velocity variations. We firstly relocated the mainshock with a 3-D crustal model for central Taiwan 

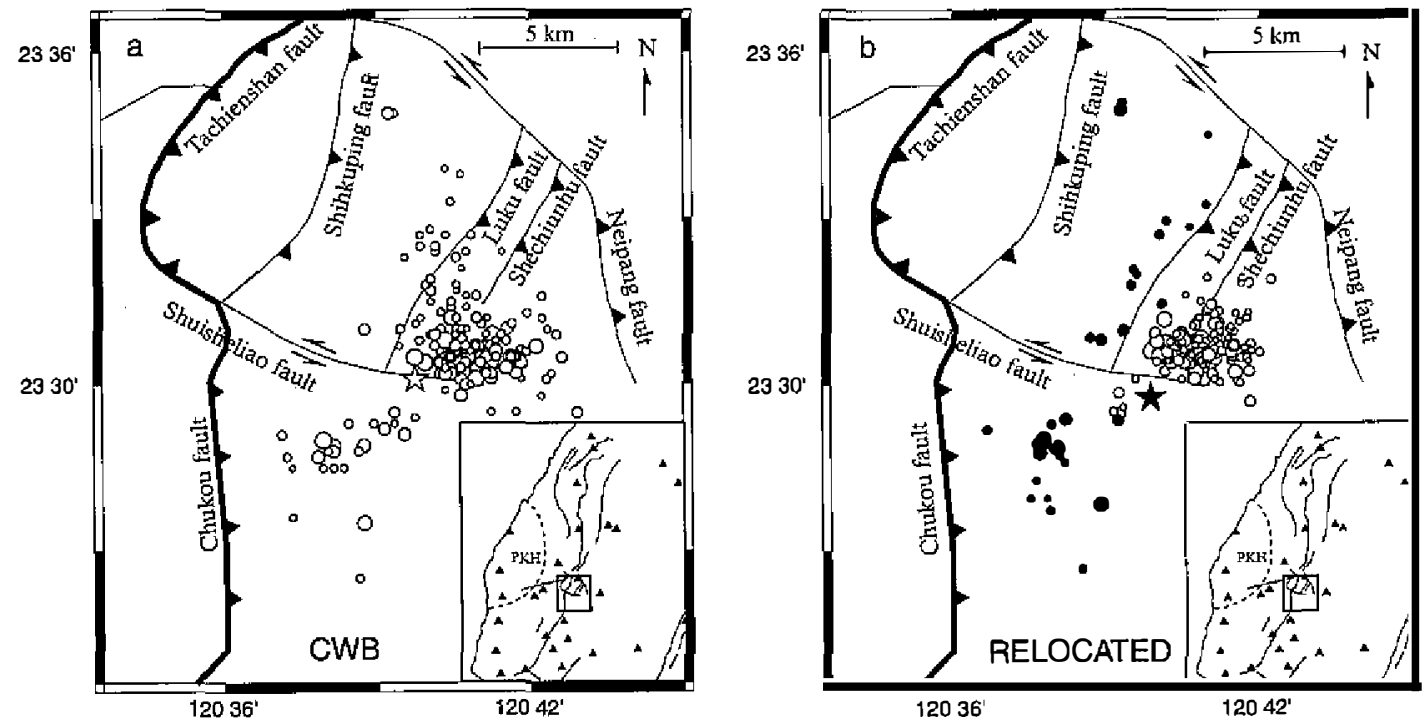

Fig. 1. (Upper) The epicenter distribution of Ruey-Li earthquake sequence included mainshock (star) and aftershocks that occurred during 24 hrs after mainshock derived from 1-D velocity structure (CWB). The major geological fault system is also shown. (Lower) The relocated epicenter distribution. The solid triangles in the figure index indicate the stations used for relocation.

derived from a tomographic study by Ho and Shin (1994) in order to improve the hypocenter location in a region of strong lateral velocity heterogeneity. Besides the first arrival times of the P-and S-wave of the mainshock given by the CWBSN, we further obtained the S-P times from the numerous nearby TSMIP free-field strong-motion stations to properly constrain the hypocenter solution. An earthquake location procedure by Virieux et al. (1988) using 3-D ray tracing was performed with the CWBSN 1-D solution as the initial guess. Far smaller RMS of travel time residuals $(0.13 \mathrm{sec}$.) of the $3-\mathrm{D}$ solution than that of $1-\mathrm{D}$ solution $(0.35 \mathrm{sec}$. $)$ shows improvement on the hypocenter location determination. The relocated hypocenter of the mainshock shows small changes but confirms that the mainshock was a shallow $(2.4 \mathrm{~km})$ event.

To relocate the aftershocks, we used a method to determine high-resolution hypocenter locations over large distances developed by Waldhouse and Ellsworth (2000). This method determines hypocenters by minimizing residuals between observed and theoretical travel-time differences for pairs of earthquakes (or double-differences) at each station while linking together all observed event-station pairs. It permits the recognition of segment boundaries and fault bends that are believed to play important roles in the initiation and arrest of a rupture. 182 aftershocks occurred roughly within the first 24- h period (except for 3 events) after the mainshock was relocated (Table 1) using the double-difference method. These 182 aftershocks were selected, each having at least 8 nearby $\mathrm{P}$ and $\mathrm{S}$ arrival-time readings. The relo- 
Table 1. The source parameters of 183 earthquakes of the Ruey-Li earthquake sequence that occurred roughly during 24 hrs after mainshock.

\begin{tabular}{|c|c|c|c|c|c|c|c|c|c|c|}
\hline Numbe & Year & & & & 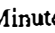 & ceond & Longitude & Latitude & Depth & ML \\
\hline 1 & 1998 & 7 & 17 & 4 & 51 & 14.79 & 120.66 & 23.50 & 2.42 & 6.2 \\
\hline 2 & 1998 & 7 & 17 & 4 & 54 & 13.71 & 120.67 & 23.51 & 4.31 & 3.7 \\
\hline 3 & 1998 & 7 & 17 & 4 & 54 & 34.30 & 120.67 & 23.51 & 2.72 & 3.7 \\
\hline 4 & 1998 & 7 & 17 & 4 & 55 & 15.49 & 120.68 & 23.51 & 3.28 & 3.1 \\
\hline 5 & 1998 & 7 & 17 & 4 & 56 & I.43 & 120.68 & 23.50 & 2.37 & 3.1 \\
\hline 6 & 1998 & 7 & 17 & 4 & 57 & 35.60 & 120.68 & 23.51 & 5.40 & 3.1 \\
\hline 7 & 1998 & 7 & 17 & 4 & 57 & 41.30 & 120.68 & 23.51 & 3.05 & 3.1 \\
\hline 8 & 1998 & 7 & 17 & 5 & 0 & 25.92 & $\$ 20.67$ & 23.51 & 5.23 & 2.4 \\
\hline 9 & 1998 & 7 & 17 & 5 & 1 & 2.53 & 120.69 & 23.51 & 9.45 & 2.2 \\
\hline 10 & 1998 & 7 & 17 & 5 & 1 & 34.56 & 120.69 & 23.52 & 6.90 & 2.5 \\
\hline 11 & 1998 & 7 & 17 & 5 & 2 & 5.36 & 120.68 & 23.51 & 5.36 & 2.9 \\
\hline 12 & 1998 & 7 & 17 & 5 & 2 & 26.24 & 120.68 & 23.51 & 9.44 & 2.7 \\
\hline 13 & 1998 & 7 & 17 & 5 & 3 & 38.41 & 120.69 & 23.51 & 3.93 & 2.5 \\
\hline 14 & 1998 & 7 & 17 & 5 & 4 & 19.46 & 120.67 & 23.51 & 3.37 & 2.7 \\
\hline 15 & 1998 & 7 & 17 & 5 & 5 & 10.08 & 120.68 & 23.51 & 4.78 & 1.8 \\
\hline 16 & 1998 & 7 & 17 & 5 & 5 & 53.55 & 120.68 & $23.5 \mathrm{I}$ & 4.94 & 1.7 \\
\hline 17 & 1998 & 7 & 17 & 5 & 7 & 59.54 & 120.69 & 23.51 & 5.85 & 2.4 \\
\hline 18 & 1998 & 7 & 17 & 5 & 9 & 7.39 & 120.69 & 23.52 & 10.04 & 1.6 \\
\hline 19 & 1998 & 7 & 17 & 5 & 10 & 30.94 & 120.68 & 23.52 & 9.18 & 1.5 \\
\hline 20 & 1998 & 7 & 17 & 5 & 13 & 22.96 & 120.67 & 23.52 & 5.17 & 2.3 \\
\hline 21 & 1998 & 7 & 17 & 5 & 14 & 2.09 & 120.68 & 23.50 & 1.55 & 1.9 \\
\hline 22 & 1998 & 7 & 17 & 5 & 14 & 29.87 & 120.65 & 23.51 & 2.87 & 2.6 \\
\hline 23 & 1998 & 7 & 17 & 5 & 16 & 25.81 & 120.65 & 23.50 & 5.18 & 2.3 \\
\hline 24 & 1998 & 7 & 17 & 5 & 18 & 32.25 & 120.67 & 23.51 & $1.5 \mathrm{E}$ & 3.7 \\
\hline 25 & 1998 & 7 & 17 & 5 & 20 & 1.71 & 120.69 & 23.52 & 7.36 & 2.1 \\
\hline 26 & 1998 & 7 & 17 & 5 & 21 & 15.85 & 120.67 & 23.51 & 4.66 & 3.2 \\
\hline 27 & 1998 & 7 & 17 & 5 & 21 & 32.50 & 120.67 & 23.52 & 5.38 & 3.4 \\
\hline 28 & 1998 & 7 & 17 & 5 & 22 & 21.74 & 120.69 & 23.51 & 2.66 & 2.9 \\
\hline 29 & 1998 & 7 & 17 & 5 & 25 & 8.52 & 120.67 & 23.52 & 6.24 & 2.9 \\
\hline 30 & 1998 & 7 & 17 & 5 & 25 & 27.58 & 120.68 & 23.50 & 1.56 & 2.4 \\
\hline 31 & 1998 & 7 & 17 & 5 & 26 & 2.34 & 120.69 & 23.50 & 2.25 & 1.7 \\
\hline 32 & 1998 & 7 & 17 & 5 & 26 & 36.11 & 120.67 & 23.51 & 5.54 & 2.8 \\
\hline 33 & 1998 & 7 & 17 & 5 & 27 & 21.76 & 120.70 & 23.51 & 8.77 & 1.9 \\
\hline 34 & 1998 & 7 & 17 & 5 & 27 & 57.91 & 120.68 & 23.51 & 5.82 & 2.5 \\
\hline 35 & 1998 & 7 & 17 & 5 & 28 & 16.82 & 120.68 & 23.51 & 5.87 & 2.5 \\
\hline 36 & 1998 & 7 & 17 & 5 & 28 & 57.11 & 120.65 & 23.49 & 5.99 & 2.9 \\
\hline 37 & 1998 & 7 & 17 & 5 & 29 & 33.18 & 120.70 & 23.53 & 15.50 & 2.1 \\
\hline 38 & 1998 & 7 & 17 & 5 & 30 & 35.47 & 120.68 & 23.51 & 7.19 & 1.6 \\
\hline 39 & 1998 & 7 & 17 & 5 & $3 \mathrm{I}$ & 20.83 & 120.68 & 23.51 & 7.23 & 0.2 \\
\hline 40 & 1998 & 7 & 17 & 5 & 33 & 41.45 & 120.68 & 23.51 & 11.53 & 1.7 \\
\hline 41 & 1998 & 7 & 17 & 5 & 33 & 52.43 & 120.70 & 23.52 & 12.86 & 1.7 \\
\hline 42 & 1998 & 7 & 17 & 5 & 34 & 26.77 & 120.68 & 23.52 & 4.87 & 1.8 \\
\hline 43 & 1998 & 7 & 17 & 5 & 34 & 53.78 & 120.69 & 23.51 & 8.05 & 1.8 \\
\hline 44 & 1998 & 7 & 17 & 5 & 39 & 3.98 & 120.69 & 23.51 & 3.59 & 1.8 \\
\hline 45 & 1998 & 7 & 17 & 5 & 43 & 50.50 & 120.68 & 23.51 & 4.28 & 2.4 \\
\hline 46 & 1998 & 7 & 17 & 5 & 44 & 38.50 & 120.67 & 23.51 & 1.44 & 0.2 \\
\hline 47 & 1998 & 7 & 17 & 5 & 46 & 5.81 & 120.68 & 23.50 & 0.78 & 3.4 \\
\hline
\end{tabular}

\begin{tabular}{|c|c|c|c|c|c|c|c|c|c|c|}
\hline ab & Year & Mont & i Das & Hou & Minu & Sceond & Longitude & Latitude & Depth & \\
\hline 48 & 1998 & 7 & 17 & 5 & 48 & 12.87 & 120.68 & 23.51 & 5.21 & 2.8 \\
\hline 49 & 1998 & 7 & 17 & 5 & 49 & 15.99 & 120.65 & 23.49 & 5.94 & 2.3 \\
\hline 50 & 1998 & 7 & 17 & 5 & 49 & 38.73 & 120.70 & 23.51 & 8.62 & 2.1 \\
\hline 51 & 1998 & 7 & 17 & 5 & 50 & 40.95 & 120.67 & 23.50 & 0.96 & 1.5 \\
\hline 52 & 1998 & 7 & 17 & 5 & 52 & 42.76 & 120.69 & 23.51 & 7.74 & 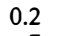 \\
\hline 53 & 1998 & 7 & 17 & 5 & 55 & 51.41 & 120.67 & 23.51 & 0.89 & 1.7 \\
\hline 54 & 1998 & 7 & 17 & 5 & 58 & 34.00 & 120.63 & 23.46 & 2.63 & 1.8 \\
\hline 55 & 1998 & 7 & 17 & 5 & 59 & 6.46 & 120.68 & 23.51 & 6.95 & 21 \\
\hline 56 & 1998 & 7 & 17 & 5 & 59 & 31.17 & 120.67 & 23.52 & 6.83 & 2.4 \\
\hline 57 & 1998 & 7 & 17 & 6 & 3 & 40.16 & 120.68 & 23.51 & 5.53 & 3.2 \\
\hline 58 & 1998 & 7 & 17 & 6 & 8 & 6.35 & 120.68 & 23.51 & 5.73 & 1.9 \\
\hline 59 & 1998 & 7 & 17 & 6 & 10 & 25.86 & 120.69 & 23.52 & 6.94 & 1.7 \\
\hline 60 & 1998 & 7 & 17 & 6 & 12 & 12.87 & 12 & 23.51 & 0.64 & 2.4 \\
\hline 61 & 1998 & 7 & 17 & 6 & 13 & 48.90 & 120.63 & 23.49 & 2.05 & 2.1 \\
\hline 62 & 1998 & 7 & 17 & 6 & 19 & 2.57 & 120.68 & 23.51 & 5.12 & 3.6 \\
\hline 63 & 1998 & 7 & 17 & 6 & 21 & 0.13 & 12 & 23.52 & 5.83 & 1.9 \\
\hline 64 & 1998 & 7 & 17 & 6 & 22 & 2. & & 23.52 & 9.25 & 2.1 \\
\hline 65 & 1998 & 7 & 17 & 6 & 22 & 57.75 & 120 & 23.51 & 7.57 & 1.8 \\
\hline 66 & 1998 & 7 & 17 & 6 & 29 & 31.69 & 12 & 23.51 & 5.11 & 0.3 \\
\hline 67 & 1998 & 7 & 17 & 6 & 33 & 29.82 & & 23.51 & 6.14 & 3.4 \\
\hline 68 & 1998 & 7 & 17 & 6 & 35 & 9.49 & 12 & 23.49 & 5.73 & 1.9 \\
\hline 69 & 1998 & 7 & 17 & 6 & 37 & 46.97 & & 23.52 & 5.09 & 1.5 \\
\hline 70 & 1998 & 7 & 17 & 6 & 44 & 29.49 & 12 & 23.51 & 0.56 & 1.9 \\
\hline 71 & 1998 & 7 & 17 & 6 & 45 & 13.11 & 120.67 & 23.51 & 0.49 & 1.9 \\
\hline 72 & 1998 & 7 & 17 & 6 & 48 & 55.95 & & 23.51 & 1.36 & 0.2 \\
\hline 73 & 1998 & 7 & 17 & 6 & 51 & 29.12 & 120 & 23.51 & 4.96 & 1.8 \\
\hline 74 & 1998 & 7 & 17 & 6 & 52 & 36.13 & & 23.51 & 5.07 & 3.5 \\
\hline 75 & 1998 & 7 & 17 & 6 & 54 & 1. & & 23.52 & 5.89 & 1.9 \\
\hline 76 & 1998 & 7 & 17 & 6 & 59 & 9.45 & 120 & 23.51 & 4.59 & 2.4 \\
\hline 77 & 1998 & 7 & 17 & 6 & 59 & 54 & & 23 & 0.36 & 1.7 \\
\hline 78 & 1998 & 7 & 17 & 7 & 3 & 59. & 12 & 23.51 & 2.16 & 1.7 \\
\hline 79 & 1998 & 7 & 17 & 7 & 4 & 15. & & & 0.83 & 0.3 \\
\hline 80 & 1998 & רe & 17 & 7 & 11 & 28. & & 23 & 0.79 & 3.2 \\
\hline 81 & 1998 & 7 & 17 & 7 & 14 & 25.76 & 120 & 23.51 & 0.18 & 1.8 \\
\hline 82 & 1998 & 7 & 17 & 7 & 17 & 37.44 & & & 5.63 & 2.1 \\
\hline 83 & 1998 & 7 & 17 & 7 & 20 & 56.21 & & 23.52 & 10.83 & 1.9 \\
\hline 84 & 1998 & $f$ & 17 & 7 & 22 & 56.15 & 12 & 23.51 & 0.18 & 1.9 \\
\hline 85 & 1998 & 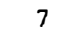 & 17 & 7 & 24 & 33.17 & & & 1.59 & 1.6 \\
\hline 86 & 1998 & 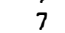 & 17 & 7 & 37 & 42. & & 23.51 & 5.71 & 2.4 \\
\hline 87 & 1998 & 7 & 17 & 7 & 38 & 19.27 & & 23.50 & 1.44 & 2.6 \\
\hline 88 & 199 & 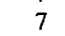 & 17 & 7 & 41 & 44. & & $23.5 \mathrm{I}$ & 6.17 & 3.4 \\
\hline 89 & 1998 & 7 & 17 & 7 & 44 & 37. & & 23.51 & 6.16 & 0.3 \\
\hline 90 & 1998 & 7 & 17 & 7 & 59 & 37. & & & 1.96 & 2.2 \\
\hline 91 & 1998 & 7 & 17 & 8 & 3 & 27.09 & & 23.48 & 0.96 & 0.3 \\
\hline 92 & 19 & 7 & 17 & 8 & 18 & 11.52 & & 23.48 & 2.13 & 0.2 \\
\hline 93 & 199 & 7 & 17 & 8 & 23 & 53.01 & 120.69 & 23.51 & 7.56 & 2.7 \\
\hline & 19 & & 17 & 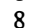 & 40 & 5464 & 120.64 & 23.51 & 2.73 & 2.1 \\
\hline
\end{tabular}


(Table 1. continued)

\begin{tabular}{|c|c|c|c|c|c|c|c|c|c|c|}
\hline mbe & - Year I & & & & & Sccond & Longitude & Latitude & Depth & ML \\
\hline 95 & 1998 & 7 & 17 & 8 & 44 & 39.91 & 120.69 & 23.51 & 7.12 & \\
\hline 96 & 1998 & 7 & 17 & 8 & 45 & 54.62 & 120.67 & 23.51 & 5.72 & \\
\hline 97 & 1998 & 7 & 17 & 8 & 46 & 36.50 & 120.69 & 23.52 & 1.56 & 2.8 \\
\hline 98 & 1998 & 7 & 17 & 9 & 16 & 14.74 & 120.69 & 23.51 & 1.62 & 2.4 \\
\hline 99 & 1998 & 7 & 17 & 9 & 29 & 53.09 & 120.66 & 23.52 & 0.20 & 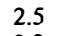 \\
\hline 100 & 1998 & 7 & 17 & 9 & 35 & 34.36 & 120.70 & 23.49 & 0.81 & 2.3 \\
\hline 101 & 1998 & 7 & 17 & 9 & 41 & 37.45 & 120.68 & 23.51 & 2.80 & \\
\hline 102 & 1998 & 7 & 17 & 9 & 45 & 22.93 & 120.67 & 23.51 & I. .88 & 80 \\
\hline 103 & 1998 & 7 & 17 & 10 & 14 & 47.22 & 120.70 & 23.51 & 7.51 & 1.8 \\
\hline 104 & 1998 & 7 & 17 & 10 & 16 & 51.64 & 120.67 & & 0.60 & 0 \\
\hline 105 & 1998 & 7 & 17 & 10 & 35 & 29.31 & 120.64 & 23.49 & 5.19 & \\
\hline 106 & 1998 & 7 & 17 & 10 & 47 & 0.99 & 120.68 & $23.5 \mathrm{I}$ & 5.78 & 1.1 \\
\hline 107 & 1998 & 7 & 17 & 11 & 26 & 43. & 12 & 23 & 2.38 & 2.6 \\
\hline 108 & 1998 & 7 & 17 & 11 & 38 & & & & 2.42 & 2.6 \\
\hline 109 & 1998 & 7 & 17 & 11 & 42 & 50.92 & 120 & 23.50 & 0.79 & 2.3 \\
\hline 110 & 1998 & 7 & 17 & 12 & 18 & 58.08 & 120 & & 0.51 & 7 \\
\hline 111 & 1998 & 7 & 17 & 12 & 23 & 48. & & & I. 6 & 0.4 \\
\hline 112 & 1998 & 7 & 17 & 12 & 41 & 26. & & & 7. & 1.8 \\
\hline 113 & 1998 & 7 & 17 & 12 & 42 & & & & 2. & 1.6 \\
\hline 114 & 1998 & 7 & 17 & 12 & 42 & 49 & & & 9. & 1.7 \\
\hline 115 & 1998 & 7 & 17 & 12 & 48 & 26. & & & & 0.2 \\
\hline 11 & 1998 & 7 & 17 & 12 & 50 & 17 & & & 8. & . \\
\hline 117 & 1998 & 7 & 17 & 12 & 56 & 42. & & & 4. & 1.7 \\
\hline 118 & 1998 & 7 & [7 & 13 & . & & & & 5. & 1.7 \\
\hline 119 & 199 & 7 & 17 & 13 & 1 & & & & 5. & 1.6 \\
\hline 120 & 1998 & 7 & 17 & 13 & 7 & 50 & & & 8. & \\
\hline 121 & 199 & 7 & 17 & 13 & 16 & & & & 6.19 & 1.6 \\
\hline 122 & 1998 & 7 & 17 & 13 & 26 & 55 & 69 & 23.51 & 6.57 & 1. \\
\hline 123 & 1998 & 7 & 17 & 13 & 29 & & & & 7. & 3. \\
\hline 124 & 195 & 7 & 17 & 13 & 43 & 17 & 68 & 23.52 & 9.2 & 2.2 \\
\hline 125 & 199 & 7 & 17 & 13 & 53 & 17 & & & 4. & 1. \\
\hline 126 & 199 & 7 & 17 & 13 & 58 & & & & 4. & 1 \\
\hline 127 & 199 & 7 & 17 & 14 & 11 & 55 & 120 & 23.52 & 5.65 & 2. \\
\hline 128 & 1998 & 7 & 17 & 14 & 16 & 18. & & & 6. & 1.2 \\
\hline 129 & 195 & 7 & 17 & 14 & 55 & & & & 7. & 1. \\
\hline 130 & 1998 & 7 & 17 & 14 & 57 & & & & 5.39 & 2. \\
\hline 131 & 1998 & 7 & 17 & 15 & 0 & & & & & 1 \\
\hline & 199 & 7 & 17 & 15 & 6 & 57 & & 23.51 & 5.94 & 1. \\
\hline 133 & 199 & 7 & 17 & 15 & 19 & & & & 8. & , \\
\hline 134 & 199 & 7 & 17 & 16 & 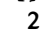 & & & & & 1. \\
\hline 135 & 199 & 7 & 17 & 16 & 10 & & & & & 1.7 \\
\hline 136 & 199 & 7 & 17 & 16 & 20 & 50 & & & 5.21 & 0.2 \\
\hline 137 & 199 & 7 & 17 & 16 & 27 & 47. & & & 0.87 & \\
\hline 13 & 19 & 7 & 17 & 16 & 59 & & & & 4. & 1. \\
\hline 13 & 195 & 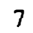 & 17 & 17 & 0 & 32 & & & 8. & , \\
\hline 14 & 199 & 7 & 17 & 17 & 14 & 44 & & & 7.69 & 1. \\
\hline 141 & 1998 & 7 & 17 & 17 & 16 & 46.28 & 120.69 & 23.50 & 7.07 & 1.7 \\
\hline
\end{tabular}

\begin{tabular}{|c|c|c|c|c|c|c|c|c|c|}
\hline Numbe & Year : & & & & & (1) & Long & Latitude & Depth \\
\hline 142 & 1998 & 7 & 17 & 17 & 21 & 7.32 & 120.68 & 23.53 & 7.74 \\
\hline 143 & 1998 & 7 & 17 & 17 & 22 & 6.36 & 120.68 & 23.52 & 6.17 \\
\hline 144 & 1998 & 7 & 17 & 17 & 26 & 25.52 & 120.63 & 23.48 & 4.59 \\
\hline 145 & 1998 & 7 & 17 & 17 & 35 & 44.48 & 120.68 & 23.51 & 5.23 \\
\hline 146 & 1998 & 7 & 17 & 17 & 47 & 1.64 & 120.69 & 23.51 & 7.06 \\
\hline 147 & 1998 & 7 & 17 & 17 & 52 & 45.80 & 120.64 & 23.44 & 5.34 \\
\hline 148 & 1998 & 7 & 17 & 17 & 55 & 29.46 & 120.69 & 23.52 & 6.00 \\
\hline 149 & 1998 & 7 & 17 & 18 & 11 & 51.78 & & 23.51 & 5.85 \\
\hline 150 & 1998 & 7 & 17 & 18 & 13 & 52.68 & & 23.58 & 12.15 \\
\hline 151 & 1998 & 7 & 17 & 18 & 14 & 42.16 & 120.69 & 23.51 & 8.26 \\
\hline 152 & 1998 & 7 & 17 & 18 & 14 & 56.36 & 12 & 23.51 & 4.42 \\
\hline 153 & 1998 & 7 & 17 & 18 & 22 & 3.16 & 12 & 3.48 & 2.80 \\
\hline 154 & 1998 & 1 & 17 & 18 & 22 & 55.20 & & 23.51 & 5.98 \\
\hline 155 & 1998 & 7 & 17 & 18 & 46 & 1 & 65 & 23.46 & 8.13 \\
\hline 156 & 1998 & 7 & 17 & 18 & 46 & 50.08 & & 23.50 & 8.77 \\
\hline 157 & 1998 & 7 & 17 & 18 & 53 & 38 & & 23.51 & 6.86 \\
\hline 158 & 1998 & 7 & 17 & 19 & 0 & 16. & & 23.51 & 5.44 \\
\hline 159 & 1998 & 7 & 17 & 19 & 59 & & & & 8.37 \\
\hline 160 & 1998 & 7 & 17 & 20 & 2 & 31.84 & & 23.55 & 4.56 \\
\hline 161 & 1998 & 7 & 17 & 20 & 10 & 47. & & 23.48 & 5.68 \\
\hline I62 & 199 & 7 & 17 & 20 & 48 & & & & 4.88 \\
\hline 163 & 1998 & 7 & 17 & 20 & 51 & 50. & 12 & 23.53 & 8.27 \\
\hline 164 & 1998 & 7 & 17 & 20 & 57 & & & & 5. \\
\hline 165 & 199 & 7 & 17 & 21 & 14 & 5 & & 3.52 & 11.12 \\
\hline 166 & 1998 & 7 & 17 & 21 & 19 & 48 & & 23.48 & 4.69 \\
\hline 16 & 199 & 7 & 17 & 21 & 3 & & & & 5.86 \\
\hline 16 & 199 & 7 & 17 & 21 & 47 & 17. & & 23.58 & 14.54 \\
\hline 169 & 1998 & 7 & 17 & 21 & 47 & 40 & & & 14.18 \\
\hline 170 & 199 & 7 & 17 & 22 & 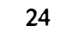 & & & 23.51 & 4.99 \\
\hline 171 & 1998 & 7 & 17 & 22 & 29 & 2 & & 23.51 & 4.02 \\
\hline 172 & 1998 & 7 & 17 & 22 & 30 & & & & 5.66 \\
\hline 173 & 1998 & 7 & 17 & 22 & 42 & 52 & & 23.51 & 0.79 \\
\hline 174 & 1998 & $r$ & 17 & 22 & 46 & 9.3 & 120 & 23.49 & 4.28 \\
\hline 175 & 1998 & 7 & 17 & 23 & 54 & & & 2351 & 496 \\
\hline 176 & 199 & 7 & 18 & 0 & 2. & 4.08 & & 23.53 & 5.72 \\
\hline 177 & 1998 & 7 & 18 & 1 & 14 & 5.12 & & & 1.78 \\
\hline 178 & 199 & 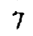 & 18 & i & 24 & & 12 & 23.51 & 0.98 \\
\hline 179 & 1998 & $f$ & 18 & 1 & 29 & 9. & & 23.52 & 8.10 \\
\hline 180 & 199 & 7 & 18 & 3 & 33 & & & 23.52 & 2.08 \\
\hline 181 & 1998 & 7 & 18 & $A$ & 58 & 24.3 & & 23.52 & 5.08 \\
\hline 182 & 1998 & 7 & 18 & 17 & 2 & 39.28 & 120.69 & 23.51 & 4.92 \\
\hline
\end{tabular}


cated hypocenters give a picture of 3-D event distribution of the Ruey-Li earthquake sequence that is somewhat different from the solutions obtained based on 1-D velocity structure. The differences between the CWBSN 1-D and the relocated 3-D solutions resulted from the strong lateral variation of crustal velocities. That the westem part of the research area shows positive values of the station correction that implies lower velocity in the Western Coastal Plain than in the Western Foothills region and is consistent with the surface geology.

Figures $1 \mathrm{a}$ and $\mathrm{b}$ illustrates the mainshock and those 182 aftershocks studied, before and after the relocation, respectively. An insert in the lower right of both figures gives the location map and nearby seismic stations. Also shown in the insert is the outline (dashed curve) of the Pekang High (PKH) which is the Tertiary basement that comes close to the surface of the western Taiwan sedimentary basin. The epicenter distribution of the relocated aftershocks shows one linear cluster and one round cluster: the linear cluster (Group A, in black dots in Fig. 1b) is extended along the direction of roughly $N 45^{\circ} \mathrm{E}$, and the $3 \mathrm{~km} \mathrm{x} 5 \mathrm{~km}$ round cluster (Group B, in open circles in Fig. 1b) is concentrated at the eastern side of the linear cluster. The vertical profile along the E-W direction (Fig. 2a) also shows two spatial alignments of hypocenters. Both Group A and Group B show narrow distributions of events with roughly vertical apparent dips. The mainshock shown by a star occurred at the upper part of these clusters. In the vertical profile along the N-S direction (Fig. 2b), Group B events still show a narrow distribution with nearby vertical apparent dip, and Group A events scatter about in the profile. These profiles demonstrate that the Group A events and the mainshock occurred over a rupture plane of nearly vertical dip. The Group B events are not distributed over a planar surface, instead, they congregate in a columnar volume of $3 \mathrm{~km} \times 5 \mathrm{~km} \times 15 \mathrm{~km}$ in dimension. The mainshock is located near the top of this "event column". This columnar distribution of the aftershocks is very peculiar. We shall discuss its nature later.

\subsection{Focal Mechanisms}

Focal mechanisms of the mainshock and 21 aftershocks (Table 2) of the Ruey-Li earthquake sequence were studied with the fault-plane solutions obtained using the first P-motion data from both short-period and strong-motion instruments. This procedure increased both the quantity and the reliability of the first motion data. The azimuths and the take-off angles of the ray paths of the direct $P$ waves were calculated with the same dynamic ray tracing technique and the 3-D velocity model used for the event relocation. The FPFIT software (Reasenberg and Oppenheimer 1985) was used to obtain the fault plane solution. Figure 3 shows the faultplane solutions of the mainshock and 21 aftershocks, the lower right insert gives the location map and nearby seismic stations. Also shown in the insert is the outline (dashed curve) of the Pekang High (PKH) which is the Tertiary basement that comes close to the surface of the western Taiwan sedmentary basin. The presence of PKH introduces a further complication to the local stress field. A large number of Group A events, including the mainshock, show oblique thrust or thrust-type faulting, and most of the fault-plane solutions in Group B show left-lateral strike-slip fault type faulting. We surmise that the mainshock and Group A events are associated with a nearly vertical east-dipping rupture plane. The Group B events are associated with a short segment of the Shuisheliao left-lateral strike-slip fault. The columnar 

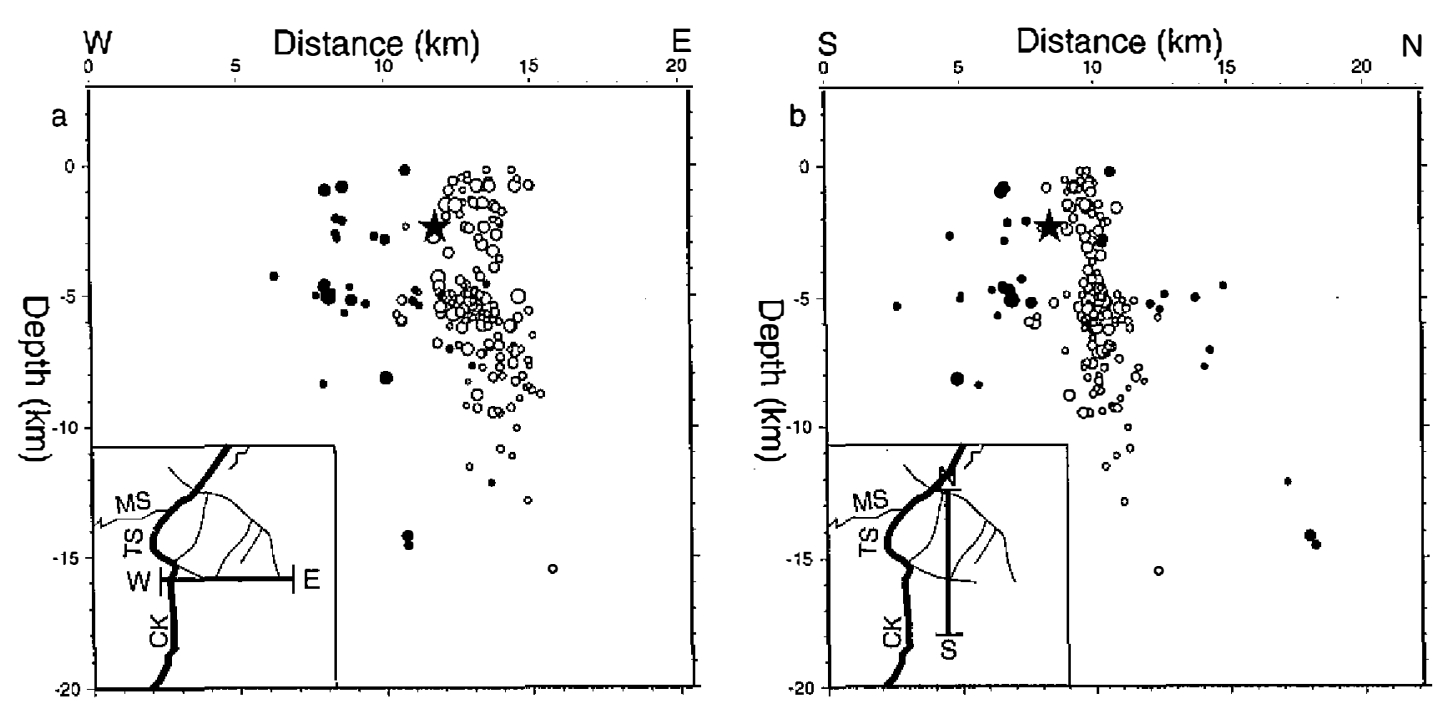

Fig. 2. The vertical profiles of relocated events along the directions of East-West and NorthSouth respectively.

distribution of Group B events mentioned above indicates a peculiar volume of stress concentration brought about by the occurrence of the mainshock - that zone of stress concentration quickly tumed into zone of stress release in terms of a concentration of aftershocks. All these different types of faulting were basically caused by the same regional maximum compress ional stress normal to the striking direction of the NE-trending tectonic line. However, it was the local change of minimum principal stress axis between vertical to horizontal direction that controlled the change of focal mechanism from thrust to strike-slip faulting. The local changes of principal stress direction reflected the local structural complexity in response to dynamic ruptures during the process of the Ruey-Li earthquake sequence.

\subsection{Stress Inversion}

Although there are several methods for inverting focal mechanisms for the stress tensor (Gephart and Forsyth 1984; Rivera and Cisternas 1990; Horiuchi et al. 1995), we applied the method described by Robinson \& Mcginty (2000) to invert the observed polarities for the orientation of principal stress axes. This method was applied to this study for two reasons. The first is that it deals with first motions directly rather than via the intermediate step of focal mechanisms. This allows the use of the numerous smaller aftershocks rather than the more limited set of larger aftershocks for which we have focal mechanisms. The second is that it invokes the Coulomb failure criterion and provides us with a more realistic view of rupture generation. There are 625 clearly determined polarities collected from the 183 events in the earthquake sequence, including events that give no fault-plane solutions. The results are given in Fig. 4, which show the horizontal $\sigma_{1}$ - and $\sigma_{3}$-axes. The best stress tensor explains $95 \%$ of 
Table 2. The fault plane solutions of 22 selected aftershocks.

$\begin{array}{crrrrrrrr}\text { Number } & \text { Depth } & \text { Strikel } & \text { Dip1 } & \text { Rakel } & \text { Strike2 } & \text { Dip2 } & \text { Rake2 } & \text { ML } \\ 1 & 2.42 & 65 & 70 & 140 & 171 & 53 & 25 & 6.2 \\ 47 & 0.77 & 85 & 90 & -170 & 175 & 80 & 0 & 3.4 \\ 48 & 5.21 & 75 & 60 & 160 & 175 & 73 & 32 & 2.8 \\ 49 & 5.94 & 65 & 65 & 140 & 174 & 54 & 31 & 2.3 \\ 62 & 5.11 & 320 & 75 & 0 & 230 & 90 & 165 & 3.6 \\ 67 & 6.14 & 70 & 70 & 150 & 171 & 62 & 23 & 3.4 \\ 74 & 5.07 & 10 & 55 & 30 & 261 & 66 & 141 & 3.5 \\ 80 & 0.78 & 350 & 65 & -20 & 268 & 72 & -154 & 3.2 \\ 96 & 5.72 & 75 & 80 & 150 & 170 & 61 & 12 & 3.5 \\ 127 & 5.65 & 20 & 80 & 30 & 284 & 61 & 168 & 2.5 \\ 130 & 6.17 & 60 & 70 & 140 & 166 & 53 & 25 & 2.1 \\ 144 & 4.59 & 45 & 55 & 100 & 208 & 36 & 76 & 2.7 \\ 147 & 5.33 & 65 & 60 & 140 & 178 & 56 & 37 & 1.8 \\ 151 & 8.25 & 75 & 85 & 160 & 167 & 70 & 5 & 2.2 \\ 154 & 5.97 & 65 & 85 & 140 & 159 & 50 & 6 & 1.7 \\ 155 & 8.13 & 10 & 45 & 100 & 176 & 46 & 80 & 3.3 \\ 158 & 5.43 & 65 & 85 & -150 & 152 & 60 & -6 & 3.0 \\ 169 & 14.17 & 10 & 55 & 70 & 222 & 40 & 116 & 2.7 \\ 173 & 0.79 & 320 & 85 & 20 & 228 & 70 & 175 & 3.0 \\ 181 & 5.07 & 45 & 55 & 140 & 161 & 58 & 42 & 1.8 \\ 182 & 4.91 & 245 & 75 & 140 & 347 & 52 & 19 & 4.5 \\ 183 & 1.48 & 250 & 85 & -170 & 339 & 80 & -5 & 4.1\end{array}$

the polarity observations. This orientation of the regional stress tensor is quite close to that inferred from shear-wave splitting (Chen and Yen 1998) and other geological and geophysical observations (Lee and Chu 1991). The $95 \%$ confidence level for $\sigma_{1}$ and $\sigma_{3}$ is obtained from 1000 resamples using a method by Michael (1987). The two stress axes are indicated by the two black dots. The tighter $95 \%$ confidence limit area of $\sigma_{1}$ implies the compression axis is better determined than $\sigma_{3}$-axis. The two groups of distribution of $\sigma_{3}$ indicate two fault types with the same $\sigma_{1}$-axis, accounting for the change of a strike-slip to a thrust faulting: the strikeslip type is dominant and the other is oblique faulting is less so. However, considering that the mainshock is an oblique rupture, the principal deformation is still dominated by a thrust-type motion. The "beach balls" show the two obtained fault planes (indicated by short bars) from inversion with iraditional focal mechanism projection. The loweer one is the optimal fault plane for having fewer polarity mismatches. The preferred fault plane shows a vertical leftlateral strike-slip fault type and is consistent with both the distribution of the Group B events and the strike of the nearby Neipang fault.

\section{TECTONIC IMPLICATIONS AND CONCLUSIONS}

The distribution of Group A and Group B events implies that these events did not occur 


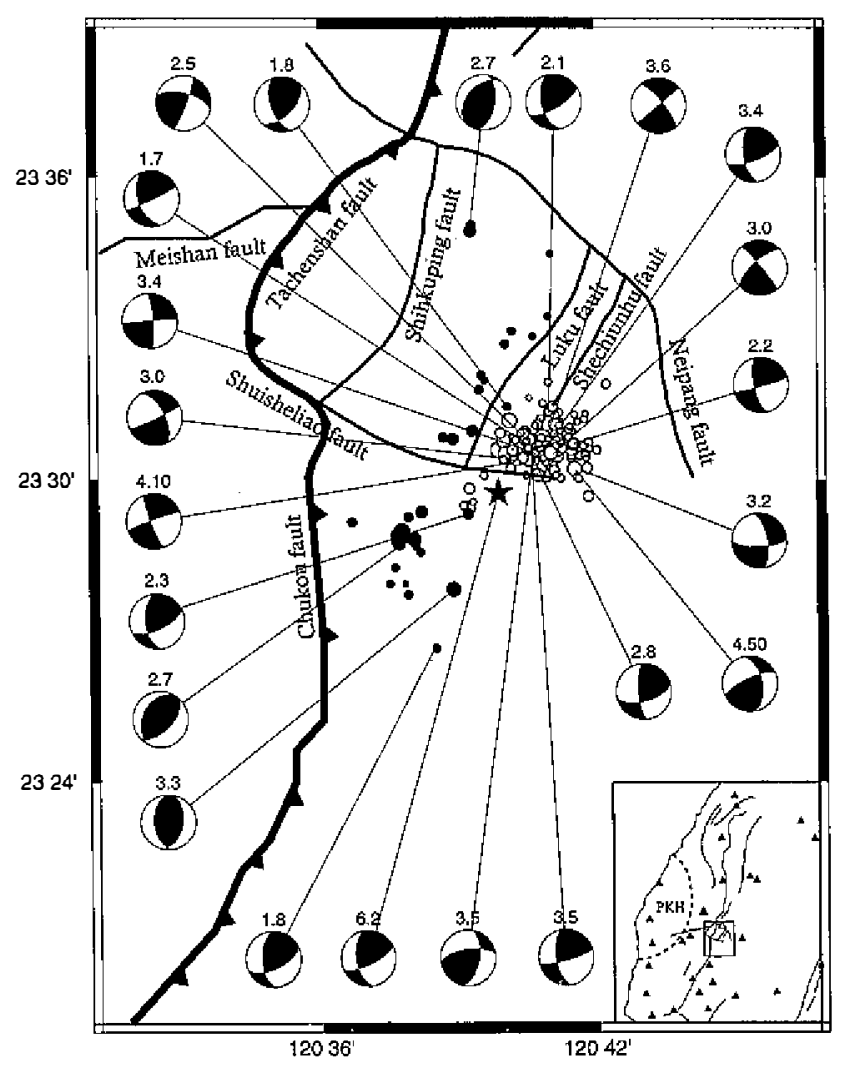

Fig. 3. Focal mechanisms of selected (22) aftershocks. The solid and open circles represent events of Group A and Group B respectively.

on the same rupture plane. Rather, they occurred along two elongated fractures zones, simultaneously activated by the mainshock. Group A shows a reverse type focal mechanism and is consistent with the attitude of the Tachienshan-Chuckou fault (or Luku fault and Shihkuping fault). Group B shows a left-lateral strike-slip motion, which is more consistent with the strike of the Neipang fault. Although these events show two types of focal mechanisms, they are due to the same principal stress orientation of a southeast-mending $\sigma_{1}$. Careful GPS measurements (Yu et al. 1997) show that the maximum shortening direction in the study area is roughly northwest, which is oblique to the strike of faults and the axis of the principal compression stress $\sigma_{1}$. We interpret the northeast-trending thrust faults as the result of lateral extrusion due to the presence of a mechanically strong Peikang High (PKH) basement that comes close to the surface (Fig. 1). The NNW-trending high angle strike-slip (tear) fault system has deformed and sometimes segmented the NNE-trending frontal thrust sheet into several fault blocks, the NW-SE compression leads the fault blocks progressively to advance northwestwardly, causing a regional clockwise rotation. Figure 5 shows a schematic diagram illustrating what we believe is happening in this region. The upper crust in this region is caught between the Peikang Basement High and the advancing of the Philippine Sea Plate indicated 


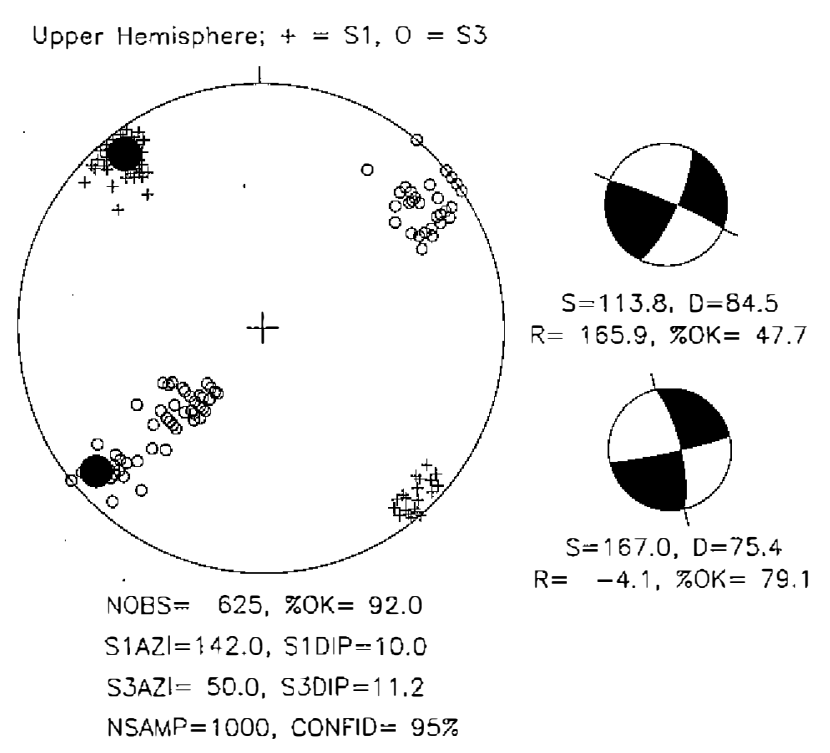

Fig. 4. $\sigma_{1}$ (pluses) and $\sigma_{3}$ (circles) axes from inversion of 625 polarities from 22 events. The $95 \%$ confidence limits are indicated by the areas defined by the symbols, with the actual result being solid circles. The "beach balls" show the focal mechanisms (upper hemisphere) corresponding to the two optimal faults (as indicated by short bar).

by the GPS velocity (open) arrows, the local deformation is represented by the deformation ellipse in response to a maximum compressional stress measured by fault-plane solutions and stress inversion. As a result, oblique slips are found on both frontal thrust and tear faults (block models at center). Note that the principle compressional stress direction observed from geodetic surveys in this area does not have to be parallel to $\sigma_{1}$, which is inferred from faultplane solutions and stress inversion. For the GPS results reflect the finite strain accumulation, while the $\sigma_{1}$-axis is determined by the dynamic motion induced by sudden rupture. In addition, the rotational motion (or the rotation tensor), which cannot be detected by the seismic sensors, should exist and would affect the finite strain accumulation measured in a large area by GSP of other geodetic surveys.

The existence of rotational strain in the study area is a key point to the above interpretation. With the geodetic deformation velocity data (Yu et al. 1997), we calculated the horizontal component of the block rotation in this area. By applying the cubic-spline technique to the 2D GPS data, we obtained the spatial derivatives of deformation velocity for grid points. Then, the angular velocity of rotational tensor on the horizontal plane for all points were calculated according to the rotation tensor:

$$
\bar{\sigma}_{z}=\frac{1}{2}\left[\frac{\partial V_{x}}{\partial y}-\frac{\partial V_{y}}{\partial x}\right]
$$




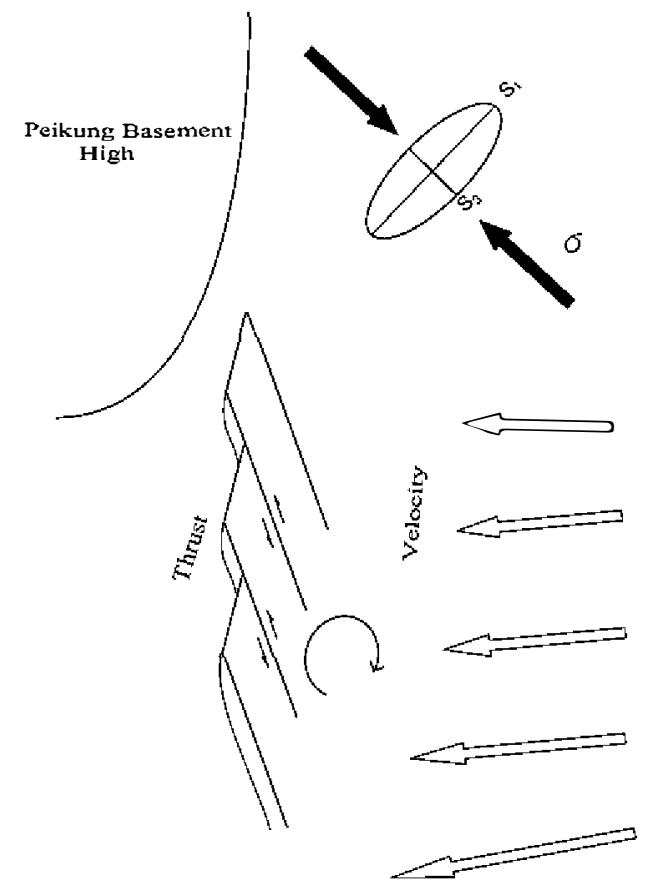

Fig. 5. A schematic diagram illustrates the block model and the relationship between the seismic and GPS observations. Please see text for further detail.

The results (Fig. 6) show that the portion with fast clockwise rotation movement extends as a band-like area with a NE trend in which the Ruey-Li earthquake sequence occurred. This explains how the block rotation process plays a role in the regional tectonics of Taiwan deformation front area. The process of fault block rotation can leave a fault in an unfavorable orientation relative to the stress field and has been observed in the Mojave area (Ron 2001). This process will lead to increasing normal stress and decreasing shear stress acting across those faults (Nur et al. 1986) until the faults lock. As the crustal deformation is continuing under the block rotation process, neighboring faults that have not moved, such as Chelungpu fault, will bear strong stress and, admittedly a hind sight now, would more likely be triggered into motion.

\section{CONCLUSION}

The Ruey-Li earthquake sequence provided us an opportunity to better understand the seismotectonics of the complex fold and thrust belt. With the analysis of events location, focal mechanisms and the direction of tectonic stress, we infer that a block rotation process is proceeding in the study area, which is supported by the well-attested GPS data. This process explains how the block rotation process plays a role in the regional tectonics of Taiwan deformation front area and leads to increasing normal stress and decreasing shear stress acting 


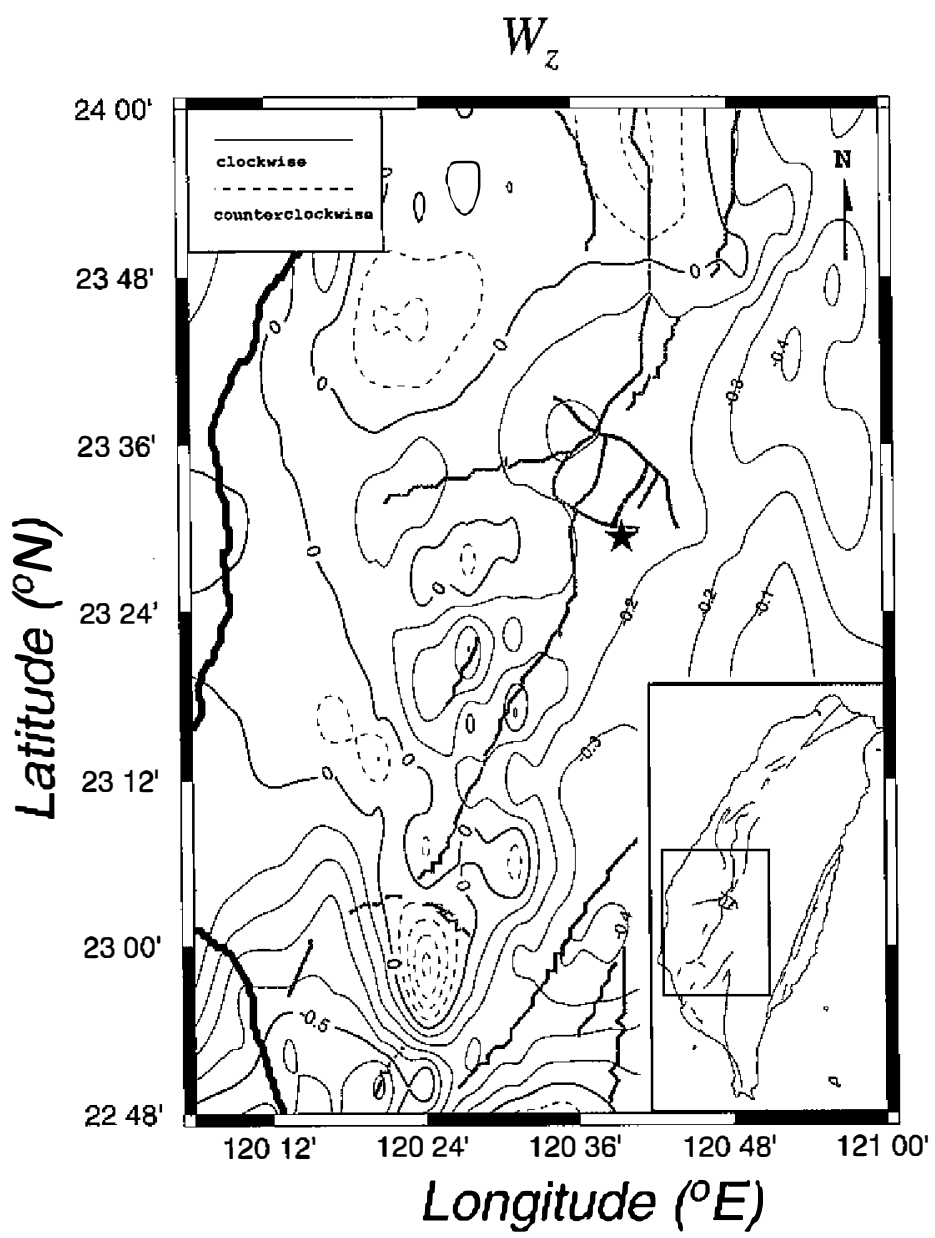

Fig. 6. The contour map of element values of rotation tensor (vertical axis) around the source area of the Ruey-Li earthquake.

across those faults. In this case, large thrust movements on neighboring faults, such as the Chi-Chi earthquake, could possibly be triggered.

Acknowledgements We would like to thank the Taiwan Central Weather Bureau for operating an excellent broadband, large dynamic range telemetered seismic network. Discussions with Dr. K. C. Chen have been most helpful. This research was funded by the National Science Council, Republic of China (Contract Number NSC90-2119-M-194-002) and Central Weather Bureau (MOTC-CWB-91-E-23), and a Central Weather Bureau, Republic of China grant on Earthquake Early waming and Strong-Motion Instrumentation. The other author (TLT) was supported by Contract Number MTOC-CWB-90-E-05, EAR-00010616 and EAR0124926. 


\section{REFERENCES}

Chen, C. H., and H. J. Yen, 1998: A preliminary study on crustal anisotropy in Chia-Nan area of Taiwan. TAO, 9, 573-588.

Chen, K. C., B. S. Huang, K. L. Wen, H. C. Chiu, Y. T. Yeh, S. N. Cheng, H. Y. Peng, T. C. Shin, R. C. Shih, and C. R. Lin, 1999: A study of aftershocks of the 17 July 1998 RueyLi earthquake. TAO, 10,605-618.

Gephart, J. W., and D. W. Forsyth,1984: An improved method for determining the regional stress tensor using earthquake focal mechanism data: application to the San Fernando earthquake sequence. J. Geophys. Res., 89, 9305-9320.

Ho, C. S., 1976: Foothills tectonics of Taiwan. Bull. Geol. Surv. Taiwan, 25, 9-28.

Horiuchi, S., G. Russo, and A. Hasegawa, 1995: Discrimination of fault plane from auxiliary planes based on simultaneous determination of stress tensor and a large number of fault plane solutions. J. Geophys. Res., 100, 8327-8338.

Huang, T. C., 1980: Oligocene to Pleistocene calcareous nanofossil biostratigraphy of the Hsuenshan Range and western foothills in Taiwan, in: T. Kobayashi et al. (Eds), Geology and Paleontology of Southeast Asia, Univ. of Tokyo Press. Tokyo, 21, 191-210.

Keng, W. P., 1986: Geology of the area between Chushan and Chiayi, central Taiwan. Bull. Central Geol. Surv., 4, 1-26 (in Chinese).

Lee, C. T., and H. T. Chu, 1991: The distribution of the Plio-Quaternary arc-continent collision in Taiwan. Taicrust Workshop Proceedings, June 10-12, 77-81.

Liu, H. C., and J. F. Lee, 1998: Explanatory text of the geologic map of Taivan: scale 1: 50000, sheet 38, Central Geol. Surv. Open-file Rept. 47pp (in Chinese).

Michael, A. J., 1987: Use of focal mechanisms to determine stress: a control study. J. Geophys. Res., 92, 357-368.

Nur, A., H. Ron, and O. Scotti, 1986: Fault mechanics and the kinematics of block rotation. Geology, 16, 675-679.

Reasenberg, P., and D. Oppenheimer, 1985: U.S. Geol. Surv. Open-file Rept., 85, 1-739

Rivera, L., and A. Cisternas, 1990: Stress tensor and fault plane solutions for a population of earthquakes. Bull. Seismol. Soc. Am., 80, 600-614.

Robinson, R., and P. J. Mcginty, 2000: The enigma of Arthur's Pass, New Zealand, earthquake 2 . The aftershock distribution and its relation to regional and induced stress field. J. Geophys. Res., 105, 16139-16150.

Ron, H., R. Freund, Z. Garfunkel, and A. Nur,1984: Block-rotation by strike-slip faulting: Structural and paleomagnetic evidence. J. Geophys. Res., 89, 6256-6270.

Suppe, J., 1980: Imbricate structure of western Foothills belt, south-central Taiwan. Petrol. Geol. Taiwan, 17, 1-16.

Tsan, S. F., and W.P. Keng,1962: The strike-slip faulting and the concurrent or subsequent folding in the Alishan area, Taiwan. Proc. Geol. Soc. China, 5, 119-126.

Virieux, J., V. Farra, and R. Madariaga,1988: Ray tracing in laterally heterogeneous media for earthquake location. J. Geophys. Res., 93, 6585-6599. 
Waldhouser, F., and W. L. Ellsworth, 2000: A double-difference earthquake location Algorithm: method and application to the northern Hayward Fault, California. Bull. Seismol. Soc. Am., 90, 1353-1368.

Yu, S. B., H. Y. Chen, and L. C. Kuo, 1997: Velocity field of GPS stations in the Taiwan area, Tectonophysics, 274, 41-59. 